- Talk 2: Role of trauma registries to improve quality of care in developing countries - case studies from three different settings - Dr. Amber Mehmood, Johns Hopkins International Injury Research Unit, USA

- Abstract: Trauma registries play an important role in performance improvement and hospital-based injury surveillance. Case studies from Pakistan, Kenya and Kampala are presented with details about inclusion, exclusion criteria, data collection platform, implementation model, funding sources and stakeholder engagement. All three registries used electronic platforms, however implementation strategies differed. Dedicated trauma registry personnel results in reliable capture of cases, complete follow up of patients and better quality of data but has higher cost of operation. Trauma registries not only helped in measuring hospital injury burden but also helped documenting the care processes with potentially impactful solutions. Implementation of trauma registries may cause both direct and indirect positive impact on trauma care in the hospital regardless of method of implementation. Long term and sustainable impact could only be seen with strong support from key hospital administrators.

- Talk 3: Developing an internet-based traumatic brain injury registry in Uganda - Dr. Olive Kobusingye, Makerere University School of Public Health, Uganda

- Abstract: The primary aim of this review was to define core variables for an internet-based data registry focused on TBI in Uganda. A comprehensive review was conducted. Six databases including PubMed/Medline, Embase, Scopus, Cochrane Reviews, System for Information on Grey Literature and Global Health Ovid were searched for literature pertaining to TBI in the African region and TBI registries in low-and middle-income countries. Thirty-five articles were identified as relevant to the focus of inquiry. The majority of the articles were from Nigeria, followed by South Africa and Tunisia. Few included definition used to define TBI. The most commonly collected core variables were demographics, injury event, initial assessment, emergency department care, in-patient care and outcome at hospital discharge.

- Discussant: Steps forward: what are the best "systems" to care for the injured in low-resource settings - Dr. Junaid Razzak, Johns Hopkins International Injury Research Unit, USA

- Q\&A - Dr. Adnan A. Hyder, Johns Hopkins International Injury Research Unit, USA

\section{Intimate Partner Violence}

\section{SU AP W2}

\section{BETTER SERVICES FOR VICTIMS OF DOMESTIC VIOLENCE. CLOSE COOPERATION BETWEEN THE PUBLIC SECTOR, NGOS AND EXPERTS BY EXPERIENCE}

Helena Ewalds. Development Manager, National Institute for Health and Welfare, Olli Humalamäki, Social Worker, The City of Mikkeli, Sirkku Mehtola, Executive Director, Viola Free From Violence

10.1136/injuryprev-2016-042156.32
Background In Finland we have for many years worked to improve the public services (health care and social services) for victims of domestic violence. The specialised services for victims of domestic violence are usually run by NGOs. One of the obstacles has been that the staff in social- and health care don't identify the victims of domestic violence. There is still lack of education but the main reason is that they don't ask about violence. Domestic violence enquiry and assessment form has been develop and used in different settings but there is still need to spread the use of the form. The aim of the project (VÄISTÖ) we are presenting includes not only the use of routine enquiry but also how to intervene in domestic violence and establish the practice and develop public services.

Methods The VÄISTÖ-project is part of the National Development Plan for Social Welfare and Health Care (Kaste Program). The purpose is that national, regional and local actors work together to create and implement good practices. This project is implemented in the municipalities of North Karelia and South Savo areas together with two NGOs Viola Free From Violence (SAUMURI-project) and Victim Support (ORAVA-Project). The roles of NGOs have been important when it comes to engaging the Experts by Experience in the development work.

The service developments that have been done are following:

1. Define the roles of domestic violence work in social- and health care public services. How is doing what and when.

2. Dictate the responsibilities and put it in the structures. For example it is your obligation to intervene in domestic violence.

3. Dictate the coordination between different agencies.

4. The service developments have only been achieved by close teamwork between professionals, experts and Experts by Experience.

Results and Conclusions The key learning from this project has been that use of routine enquiry helps professionals in social- and health care settings better intervene in domestic violence. The professionals need an ongoing education in using the enquiry and assessment form. Despite education the professionals also need some expert to consult in situations when domestic violence is disclosed. In public services we also need professionals who are experts in domestic violence issues. One of the key findings in this service model is that the clients are getting more coordinated and comprehensive help. The clients are not as often as earlier redirected from one place to another.

\section{HEARING THE VOICE OF DISABLED PEOPLE. DEVELOPING BETTER SERVICES OF DOMESTIC VIOLENCE}

${ }^{1}$ Sisko Piippo, ${ }^{2}$ Birgitta Huisman-Laine. ${ }^{1}$ University of Eastern Finland, VIOLA Free From Violence, Saumuri Project, Finland; ${ }^{2}$ VIOLA Free From Violence, Saumuri Project, Finland

\subsection{6/injuryprev-2016-042156.33}

Background The New Social Welfare Act in Finland highlights citizens' equal access to the services, as well as municipalities' responsibility to collect users' experiences from service system and organise specialised services for victims of domestic violence. Description of the problem As a marginal group, particularly people with disability are very vulnerable. They position is weak in the service system in getting help as a victim of domestic violence. Also, domestic violence is an untold problem in their own 